\title{
Decorticate Spasticity: A Re-examination using Quantitative Assessment in the Primate
}

\author{
R. R. TASKER, F. GENTILI, K. SOGABE, M. SHANLIN AND P. HAWRYLYSHYN
}

SUMMARY: Decorticate spasticity in the squirrel monkey was chosen as a convenient laboratory model of spasticity capable of quantitative assessment upon which to evaluate various currently popular clinical spasmolytic measures. The effects of a wide variety of cortical lesions were studied involving primary and supplementary motor, premotor and parietal cortex unilaterally and bilaterally, measuring muscle tone with the evoked integrated E.M.G. technique. Measurable spasticity resulted only if primary motor cortex was ablated bilat-

RÉSUMÉ: La spasticité de décortication chez le singe fut choisie comme modèle de laboratoire convenable pour la spasticité, étant capable d'évaluation quantitative des diverses mesures spasmolytiques généralement populaires cliniquement. Les effets d'une grande variété de lésions corticales furent étudiés, impliquant le cortex moteur primaire et supplémentaire, et le cortex pré-moteur et pariétal unilatéralement et bilatéralement, et mesurant le tonus musculaire par technique EMG intégrée. Une spasticité mesurable ne se rencontrait que si le cortex moteur primarie erally usually but not always preferentially involving biceps brachii and quadriceps. Resulting postures were variable offering no justification for the term "decorticate posture". The integrated evoked E.M.G. was proportional to rate of stretch and chiefly phasic in type as in hemiplegic man. Stereotactic dentatectomy resulted in profound ipsilateral reduction in this spasticity, but was without effect in intercollicular or anemic decerebrate cats. The mechanism of the spasticity and of the cerebellar effects are discussed.

était enlevé bilatéralement, impliquant préférentiellement les biceps brachiaux et les quadriceps. Les postures résultantes étaient variables, n'offrant pas de justification pour le terme "posture de décortication." L'EMG intégré évoqué était proportionnel au rythme d'étirement et de type surtout phasique comme chez l'homme hémiplégique. La dentatectomie stéréotactique résulta en une réduction ipsilatérale marquée de la spasticité, mais fut sans effet chez les chats décérébrés par lésions intercolliculaires ou par anémie.
From the Department of Surgery, Clinical Sciences Division and Institute of Medical Science, University of Toronto, Neurosurgical Division, Toronto General Hospital, Toronto, Ontario, Canada.

This work was supported by a grant from the Medical Research Council of Canada.

Reprint requests to Dr. R. R. Tasker, University Wing No. 121, Toronto General Hospital, Toronto, Ontario.

\section{INTRODUCTION}

The scientific publications concerned with spasticity read like a history of neurology and cannot fail to evoke a sense of humility in the contemporary reviewer containing as they do the writings of many of the great neuroscientists of the past century. Spasticity has always been recognized as a major affliction. Multiple sclerosis and central nervous system trauma are common causes, the incidence of spastic hemiplegia resulting from cerebrovascular disease is unquestioned and that of cerebral palsy, $60-80 \%$ of the spastic type, still stands at 1.6 per 1,000 live births (Martin, 1960).

Renewed interest in spasticity has been associated with advances in physiology, the development of methods for measuring muscle tone, the synthesis of spasmolytic drugs, and the introduction of surgical techniques such as; pulvinarectomy (Cooper et al., 1971, 1973 a), cerebellectomy and dentatectomy (Crosby et al., 1966; DelmasMarsalet and Van Bogaert, 1935; Divitiis et al., 1972; Hassler and Riechert, 1961; Heimburger, 1967, 1969, 1970a, 1970b; Heimburger and Whitlock, 1965; Hitchcock, 1973; Kraus et al., 1970; Krayenbühl and Siegfried, 1972; Laitinen, 1970; Nadvornik et al., 1972; Nashold and Slaughter, 1969; Nashold et al., 1969; Riechert, 1972; Schneider and Crosby, 1963; Siegfried, 1971; Siegfried et al., 1970, Toth, 1961; Zervas, 1970; Zervas et al., 1967a, 1967b) and cerebellar pacing (Cooper, 1973; Cooper et al, 1973b; Cooper and Gilman, 1973).

Yet there appeared to be no reproducible laboratory model with a sufficient degree of spasticity capable of quantitative evaluation upon 
which the effects of spasmolytic measures could be studied. Since it seemed a simple matter to ablate a controlled area of cerebral cortex to a controlled depth under direct vision and then to follow the consequences qualitatively and quantitatively, it was decided to study the spasticity produced by decortication in the primate.

Of the methods available (Pedersen, 1974) for measuring spasticity, an adaptation of the evoked integrated E.M.G. technique (Burke et al., 1970) for use in the animal was considered the most satisfactory. Not only does it permit direct measurement of the E.M.G. elicited by both phasic and tonic stretch, but also the slope of the linear relationship between integrated evoked E.M.G. and rate of stretch is a direct measure of the activity of the Ia spindle afferents.

Of the various secondary procedures proposed for the relief of spasticity, it was decided to investigate stereotactic dentatectomy first since this procedure had been used so widely clinically and since pulvinectomy (Brown, 1973) had proven disappointing in the relief of human hemiplegic spasticity.

\section{THE SUBSTRATE OF DECORTICATE RIGIDITY}

As early as 1869 Hughlings Jackson had reported: - "The facts seem to show that the forepart of the brain serves in the motor aspect of the mind, and we may fairly well speculate that the posterior serves in the sensory" thus launching a voluminous conflicting literature on the substrate of decorticate spasticity.

Though much of the earlier work performed on subprimates seemed to suggest that unilateral decortication resulted in spasticity (Bard et al., 1934; Bard and Rioch, 1937; King, 1927; Langworthy, 1928; Laughton, 1928; McKibben, 1929; McKibben and Wheelis, 1932; Olmsted and Logan, 1925; Warner and Olmsted, 1923; Woolsey, 1933) there was uncertainty as to whether this spasticity arose from lesions of motor or premotor cortex.

But such workers as Dusser de
Barenne and Magnus (1920) and Schaltenbrand and Cobb (1931) failed to find spasticity after unilateral subprimte decortication and Magnus and Rademaker (1923) found spasticity only when subcortical damage occurred. Moreover the illustrations of Bard and Rioch's cats show extensive subcortical damage.

King (1927), Langworthy (1928), Olmsted and Logan (1925), Snider and Woolsey (1941) and Woolsey (1933), though they found spasticity after unilateral removals of cortex in subprimates, reported maximal muscular hypertonia only if ablations were bilateral. And Fulton (1937) stated that under no circumstances was this spasticity comparable to that seen in man.

Though Leyton and Sherrington (1917) had studied the effects of unilateral premotor and motor decortications in anthropoid apes, they stressed the minimal nature of the resultant disability and never mentioned spasticity. The intensity of investigations of primate decorticate spasticity gained momentum with Fulton. Though it is generally stated that Fulton's work (1943) established that cortical removals in monkeys led to spasticity in the contralateral limbs when premotor area 6 , not motor area 4 was affected, a somewhat different conclusion might be reached from a reexamination of his published data. Kennard and Fulton (1933) studying the effects of premotor and fractional motor ablations in chimpanzees clearly produced only transient hypertonia if the premotor areas were removed, unilaterally or bilaterally, never removed the entire motor area bilaterally, appeared to find spasticity maximal only after bilateral combined motor-premotor lesions, and interject confusion as to what they meant by spasticity by commenting: "Marked spasticity of both upper extremities appeared with moderate increase in resistance to passive manipulation". They concluded "in monkeys and baboons" after "complete bilateral extipation of Areas 4 and 6 forced grasping and spasticity are extreme".

Fulton and Kennard (1934) found that premotor ablations resulted only in temporary spasticity, permanent spasticity depending upon bilateral removal of both motor and premotor cortices. Welch and Kennard (1944) in reviewing experience up to that time clearly recognized that a unilateral combined lesion of area 4 and 6 produced greater spasticity than the minor degrees resulting from lesions of either area 4 or 6 alone, that hemispherectomy resulted in greater spasticity than lesions of area 4 and 6 together and that bilateral lesions of areas 4 and 6 produced marked spasticity, views also advanced by Bucy and Fulton (1933).

Bieber and Fulton (1938), however, failed to find what they considered spasticity in some of their animals after a combined motor and bilateral premotor lesions, work that is impossible to reconcile with the rest though the actual protocols suggest spasticity.

Walshe (1935a) took issue with Fulton over the differential effects of motor and premotor lesions in spasticity, maintaining that Fulton's (1935) definitions of the areas involved were erroneous.

Thus Fulton's work established that significant spasticity depended on bilateral ablation of motor and premotor cortex. His major contribution was the separation of the pyramidal symptoms, such as paralysis, from the extrapyramidal, such as increased muscle tone, no matter which portion of the cerebral cortex, area 4 or 6 , gave rise to them.

This dichotomy was supported strongly by Tower's $(1935,1940)$ observations which, for the first time, left no doubt that unilateral or bilateral pyramidotomy in the cat or monkey which selectively severed the pyramidal system did not produce spasticity, findings since confirmed by many workers (Gilman and Marco, 1971). Wagley (1945), however, reported that pyramidotomy rendered hip adductors spastic, Denny-Brown (1963) that section of the middle third of the pyramid resulted in transient spasticity of extensors and flexors, and Growden et al. (1967) that spasticity 
developed in forelimb flexors, hip adductors, and ankle extensors and invertors after unilateral or bilateral pyramidotomy in monkeys. Various effects upon tendon reflexes were reported. Similarly most observers such as Bucy $(1964,1966)$ and Maspes and Pagni (1964) failed to produce spasticity in monkeys or man by unilateral or bilateral section of pyramidal fibers in the middle third of the cerebral peduncle though Walker and Richter (1966) found a delayed increase in tone in monkeys. Cannon et al. (1944) though reporting digital extensor spasticity after pedunculotomy found that more extensive spasticity ensued after an additional ablation of contralateral area 4S. (See below.)

The search for the substrate of spasticity continued with Hines (1936, 1937, 1960) who attributed spasticity in the macaque to removal not of area 6 , but of a $3 \mathrm{~mm}$. strip of cortex along the rostral margin of area 4 which came to be known as the suppressor strip or area 4S. Hines' statements are difficult to interpret, but it would appear that bilateral removal of this strip area was necessary to produce maximum spasticity.

Denny-Brown and Botterell (1947) reported studies made earlier upon macaques after unilateral removals of area 6 and fractionated ablations of area 4 . They concluded that spasticity resulting from lesions of area 4 was more marked if some portion of area 4 was preserved to prevent pyramidal "shock", the degree of spasticity being particularly dependent upon lesions of the rostral edge of area 4 centered on the superior precentral sulcus. No conclusions were reached concerning the relative effects of bilateral ablations.

Travis (1955a) then re-examined the whole question of decorticate hypertonia using physiological rather than cytoarchitectronic criteria. Amazingly, she found that if the primary motor cortex of the macaque was mapped out by stimulation and then ablated unilaterally or bilaterally, no spasticity resulted. One can only comment that the staged ablations involved only small portions of cortex at a time and that the illustrations of bilaterally ablated animals suggest a degree of disability less than the present authors might have expected and possibly a more critically restricted definition of what constituted primary motor cortex. Woolsey (1943) had previously reported that a monkey kept alive for 161 days after bilateral decortication had become spastic.

Travis (1955b) then studied the effects of removing the supplementary motor cortex as mapped physiologically. Unilateral ablations resulted in slight resistance to protraction and abduction of both shoulders. Bilateral simultaneous removal of the supplementary motor area in 2 monkeys produced modest resistance to passive movement with flexion deformities of the knees and elbows, an effect not observed if the ablations were staged. It appears from her report that bilateral removal of the supplementary motor area combined with an unilateral ablation of motor cortex resulted in greater spasticity than when motor cortex was unaffected. Bilateral lesions of $4 \mathrm{~S}$ and of the supplementary motor area seemed to give similar results but bilateral removal of area 6 did not change the effects of a previous ablation of primary motor cortex on both sides. However, after a subsequent extended study, Travis and Woolsey (1956) concluded that tone was not increased after unilateral aspirations of the primary and/or supplementary motor cortex, significant hypertonia occurring only after removal of both primary and supplementary cortex bilaterally.

Coxe and Landau (1965) were able to find only slight variable hypertonia at the shoulders after removing both supplementary motor areas in monkeys. Denny-Brown (1963, 1965) found only soft plastic resistance to flexion of proximal joints in the upper and lower extremities after bilateral ablations of the supplementary motor area though Gilman et al. (1974) was ready to concede that hypertonia in his monkeys that followed unilateral removal of primary motor cortex was due to inadvertent damage to white matter connecting with the supplementary cortex.
Kruger and Porter (1958) and Pribram et al. (1956) found slight spasticity after both precentral and postcentral lesions, the effects being additive.

Meanwhile Denny-Brown's thinking about muscular hypertonia was changing, introducing a new concept, a distinction between spasticity and rigidity, or dystonia as it was later called. This idea appeared first in Fulton's (1937) review after the two men had worked together. In this publication Fulton first reviewed his thinking about spasticity much as he had done in a review the year before (Fulton, 1936). Removing the posterior portion of area 4 in macaques resulted only in distal or digital spasticity, which spread to more proximal muscles if Hines' area $4 \mathrm{~S}$ was also included. If the whole of area 4 was removed spasticity became more marked, becoming enduring and widespread only if areas 4 and 6 were removed together. Ablations of area 6 unilaterally also resulted in transiently increased muscle tone, the effects being somewhat longer lasting after bilateral ablations, but the effect differed from the spasticity to which all previous work referred. Fulton (1937), crediting Denny-Brown with the observation, stated that the resistance of muscles to passive stretch after lesions of area 6 "is not akin to spasticity as such, but is similar to true extrapyramidal rigidity; that is, it is plastic and equal in quantity through all phases of the passive movement from beginning to end, and tends to be evenly distributed in flexors and extensors". This was in contrast to the predilection of spasticity for extensors and its variability throughout the range of joint excursion.

Denny-Brown (1963) pursued this dual concept equating the spasticity resulting from his superior precentral sulcal, Hines' 4S, and Fulton's area 6 lesions and attributing the discrepancy to Fulton's use of an incorrect cytoarchitectronic map. He could not confirm that lesions of supplementary cortex resulted in spasticity, but only in mild rigidity like that resulting from lesions of area 6 of which the supplementary motor cortex was part. Moreover area 6 
was not the only region whose ablation resulted in rigidity. DennyBrown (1963, 1964, 1965) and Denny-Brown et al. (1965) found similar effects after parietal lesions, significant only if they were bilateral, and which were additive to those of ablations of area 6. Since rigidity was not abolished by deafferentation (Denny-Brown, 1964, 1965; Gilman and Van Der Meulen, 1966) it was attributed to direct alpha motoneuron drive. These latter authors distinguished the two states of hypertonia by demonstrating a much greater activity in spindle afferents in hindlimb extensors than in flexors in spastic monkeys but similar levels of activity in rigid or dystonic monkeys. Curiously Gilman et al. (1974) found that after combined unilateral ablations of areas 4 and 6 , despite the presence of spasticity, spindle afferent activity never increased above normal, a result attributed to algebraic summation of excitatory and inhibitory effects on spindles of the area 6 and area 4 ablations respectively.

Perhaps the most illuminating work in the whole field has been that of Mettler (1943) who concluded that unilateral decortication, no matter how extensive, resulted in only slightly increased muscle tone and then only when area 4 was involved, unilateral lesions of area $4 \mathrm{~S}$ or of premotor cortex being without effect. Bilateral cortical ablations (Mettler 1944) likewise produced little if any spasticity, unless the rostral part of area 4 was removed on both sides when it became striking. No spasticity was seen after bilateral lesions of area 6 alone or of the caudal portion of area 4 and lesions of area 6 failed to increase spasticity after bilateral lesions of area 4. Spasticity occurred after unilateral lesions only if there was accompanying damage to subcortical structures (Mettler, 1943), the severity becoming greater as striatum, pallidum and subthalamus respectively were included in the lesion. Crosby et al. (1966) reached identical conclusions.

Observations in man have been infrequent. Förster (1934, 1936) and Sachs (1935) reported hypertonicity after unilateral lesions of motor cor-
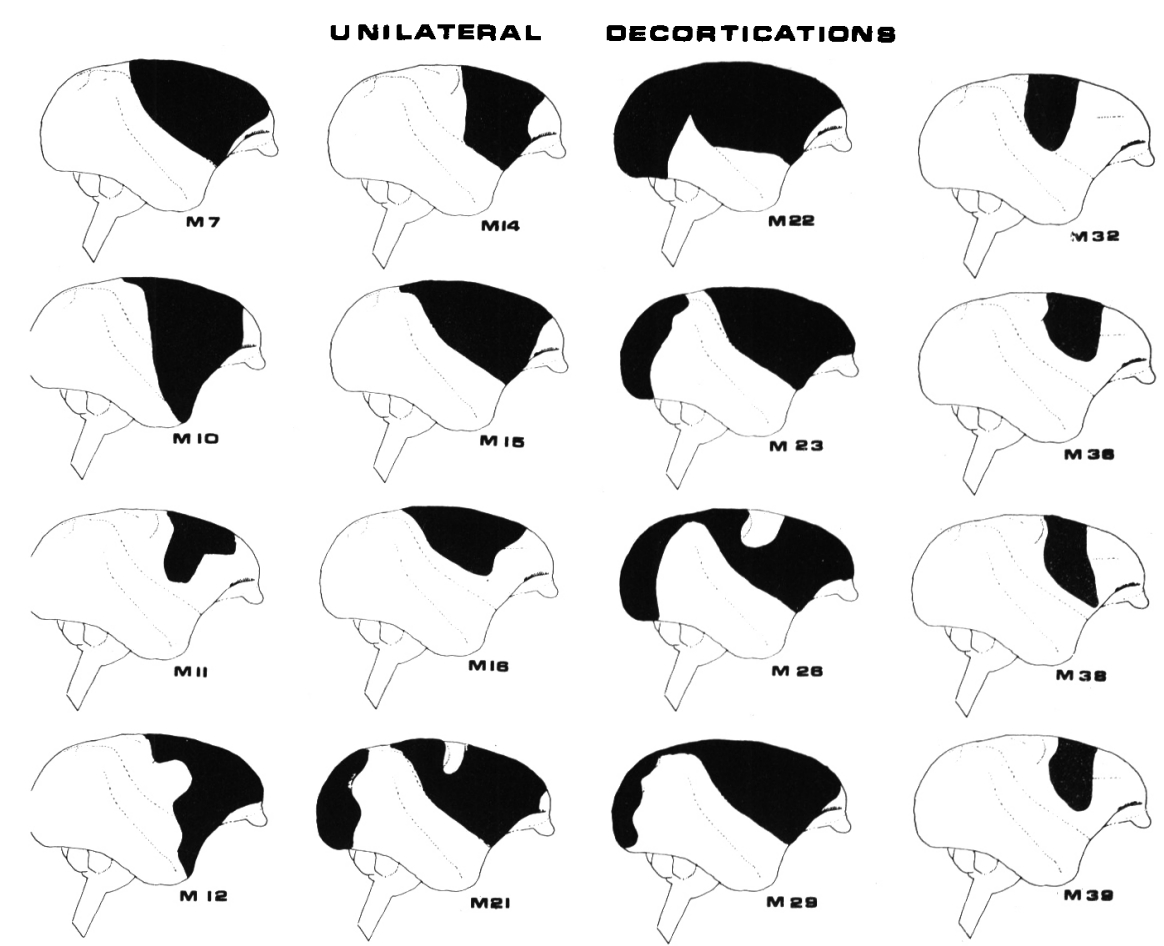

Figure 1-Extent of unilateral cortical ablations based on autopsy specimens in a preliminary series of 16 squirrel monkeys.

tex and it is clear from the attacks he made on Fulton that Walshe (1935a) agreed, reporting (Walshe, 1935b) a patient with slightly increased tone at the knee and markedly increased extensor tone of the foot after contralateral ablation of the motor cortex on the medial wall of the hemisphere. Penfield and Evans (1935) also described spasticity after unilateral lesions of the human cortex. The author has never seen striking spasticity after purely cortical unilateral lesions in man. Rasmussen (1972) has written that he has not seen spasticity after premotor cortical lesions in man.

From this review we have concluded that truly significant spasticity does not usually result from unilateral cerebral cortical lesions unless deeper structures have also been damaged, though hyperreflexia, postural changes and mild hypertonicity may appear. Only when the motor cortex has been removed on both sides do purely cortical lesions result in striking spasticity. Discrepancies in the literature are probably largely due to differing criteria for "spasticity" which to us means increased resistance to stretch. Whatever the exact substrate, spasticity is an extrapyramidal effect which Fulton recognized as distinct from the pyramidal effect of paralysis.

With this background we undertook a series of experiments to examine the effects of decortication in the squirrel monkey (Saimiri sciureus). This relatively inexpensive tractable animal whose semi-lissencephalic brain is convenient for cortical mapping, has been the subject of several physiological (Welker et al., 1957; Benjamin and Welker, 1957) and cytoarchitectronic reviews (Akert, 1964; Miles and Blomquist, 1960; Rosabal, 1967; Sanides, 1968) as well as of a brain atlas by Emmers and Akert (1963). Moreover, in this species the supplementary motor cortex extends widely over the convexity of the hemisphere well separated from the primary motor area.

First a preliminary study was made of unilateral cortical ablations of varying degree performed by subpial suction in 16 monkeys and of bilateral ablations in 10 , as shown in Figures 1 and 2, in an attempt to re- 
produce the spastic and dystonic effects described by Denny-Brown et al. (1965) and Gilman and Van der Meulen (1966). These included unilateral ablations of the motor cortex intended to produce spasticity, various unilateral and bilateral ablations of premotor and parietal cortex sparing the motor cortex intended to produce dystonia, as well as bilateral excisions of motor cortex, all planned on the basis of the physiological maps (Welker et al., 1957; Benjamin and Welker, 1957). In one baboon (Papio papio) staged, bilateral, supplementary motor ablation was performed incidentally damaging one primary motor cortex.

The results were clear. Permanent disability was seen only after dam- age to motor cortex when, after an initial 1 to 4 weeks of contralateral limb hypotonia, the animals regained a certain degree of function always maintaining an abnormal posture similar to that of the human hemiplegic. The hip and shoulder remained protracted, the elbow markedly flexed, the knee slightly. Posture varied in distal joints, the knee jerk was hyperactive, and placing reactions were absent. The normal limb was always preferred, used first and reserved for fine tasks though the affected one readily assisted in climbing, feeding and locomotion.

Apart from mild hypertonia that proved impossible to distinguish quantitatively from normal, none of these animals showed significant spasticity as long as one primary motor area was spared. Significant spasticity developed only in animals M32 and M36 whose motor areas were both ablated.

We next compared the effects of removing motor and supplementary motor areas according to the published physiological maps as illustrated in Figure 3. Unilateral ablations of primary motor cortex were carried out in 2 monkeys, of primary and supplementary in 3. Bilateral ablations of primary motor cortex were performed in 20 , of supplementary in 6, of both primary and supplementary in 16. Followup ranged up to 6 months after unilateral to 2 after bilateral operations.

Again results were clear. Animals
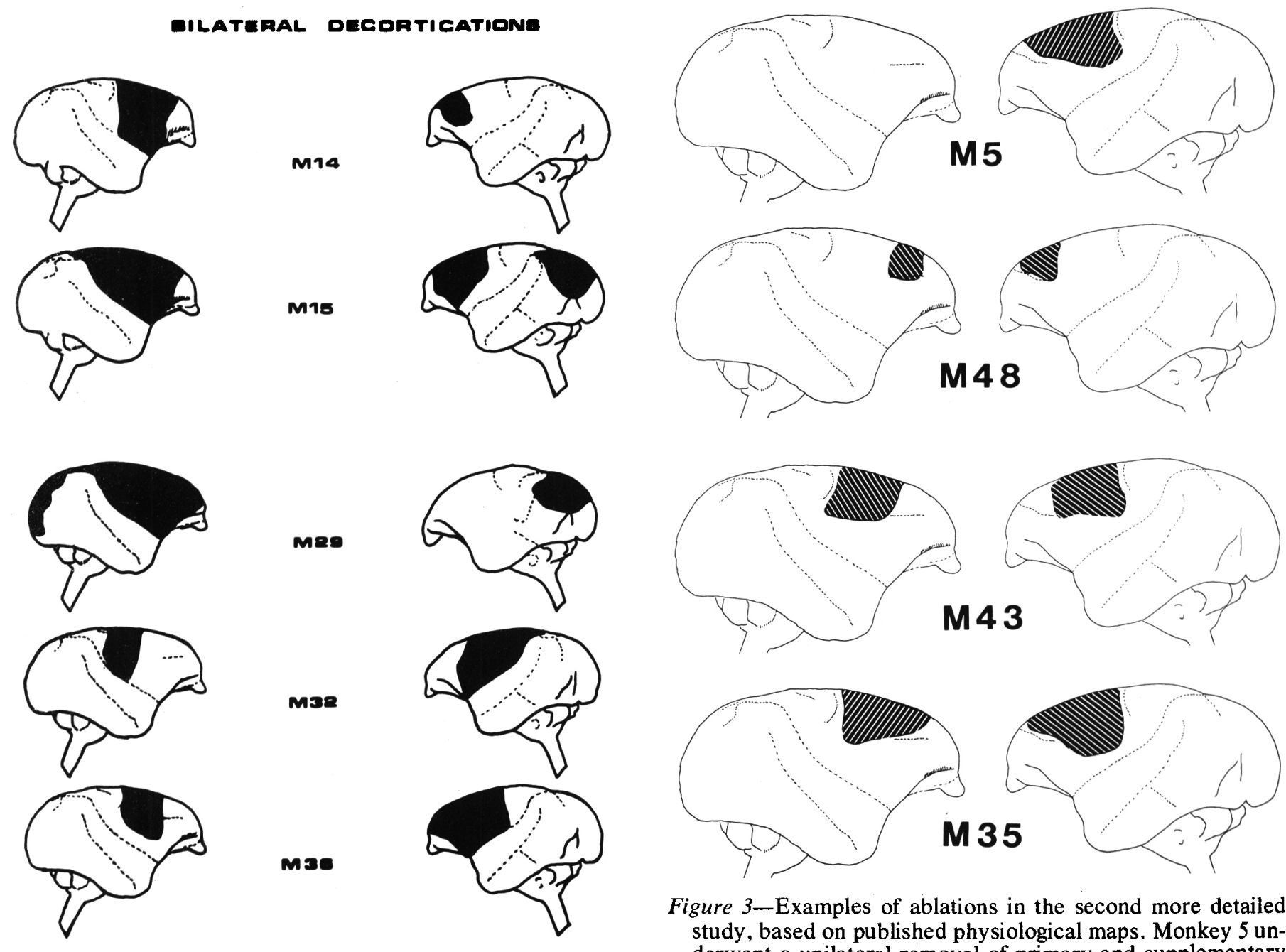

Figure 3-Examples of ablations in the second more detailed study, based on published physiological maps. Monkey 5 underwent a unilateral removal of primary and supplementary motor cortex, M48 of supplementary, M43 of primary and M35 of both primary and supplementary motor cortex bilaterally.

Figure 2-Extent of bilateral cortical ablations in a preliminary series of 10 squirrel monkeys. 

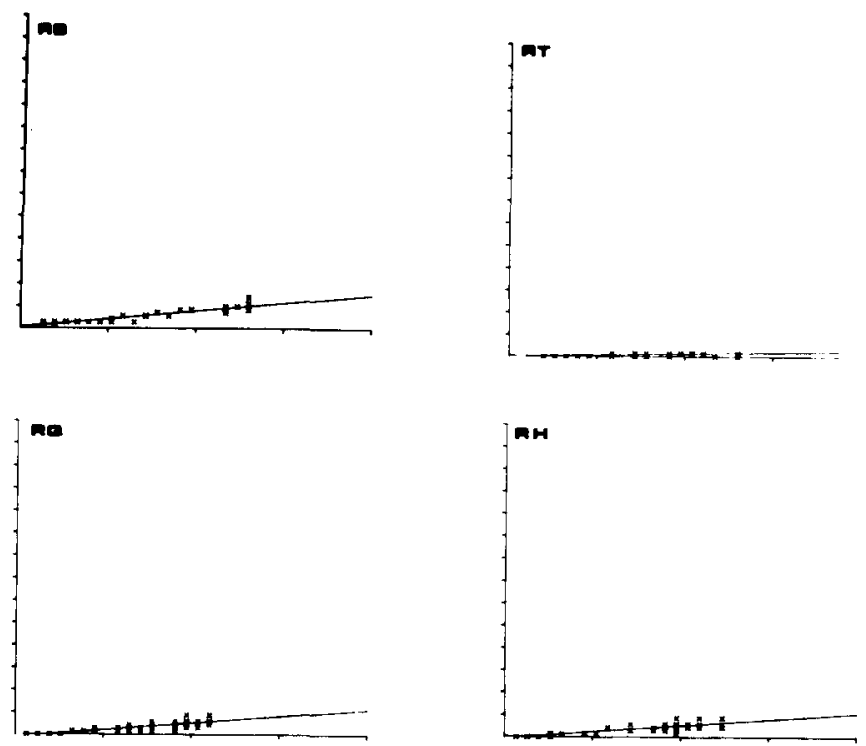

Figure 4-Computer plot of integrated evoked E.M.G. (ordinate) against rate of muscle stretch (abscissa) for M17 a normal monkey. RB, RT, RQ, RH, indicating right biceps, triceps, quadriceps and hamstrings respectively. There is virtually no evoked E.M.G. activity.
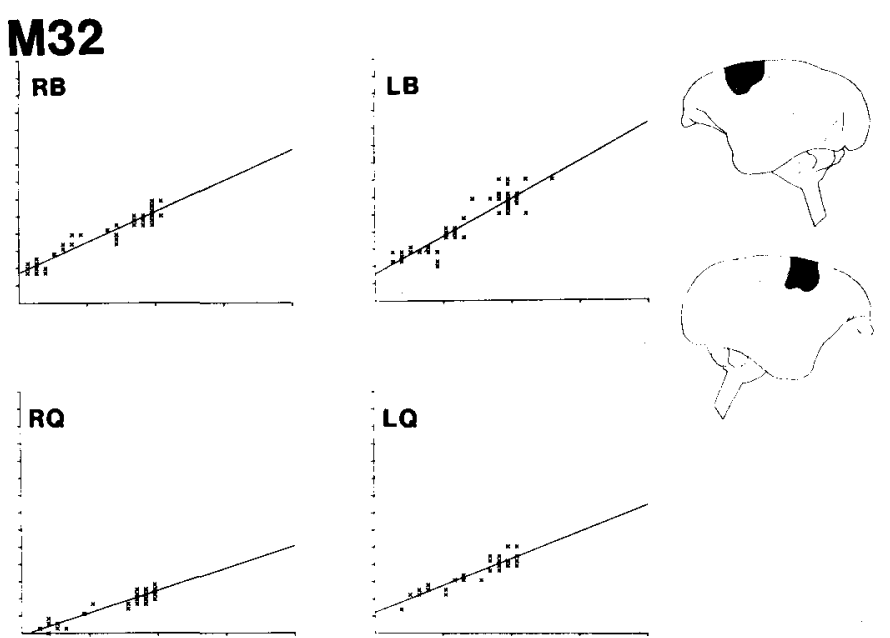

Figure 5-Same as Figure 4 after bilateral excision of primary motor cortex. Plots for right and left biceps and quadriceps. There is striking evoked E.M.G. activity, proportional to rate of stretch. sustaining bilateral ablations of primary motor cortex were helpless and dependent on intensive care as long as they lived. Though they usually assumed a posture with flexed elbows, protracted shoulders and extended knees going on to flexion contractures of the elbows and knees, a variety of other postures was also seen there being no correlation with the responsible lesions. Added lesions of the supplementary motor cortex did not alter the result. These observations suggested to us as they did to Mettler (1967) that there is little justification for the use of the terms "decorticate" and "decerebrate" postures.

The results with respect to spasticity were again definite. All 37 animals with bilateral ablations of primary motor cortex demonstrated striking spasticity regardless of whether supplementary motor cortex was involved. One of the remaining 11 monkeys, with an unilateral primary motor ablation, demonstrated hypertonicity of the biceps only.

Careful quantitative assessment was now carried out using an adaptation of the integrated evoked E.M.G. technique for use in the unsedated monkey restrained in a chair, the difficulties of which are well described by Gilman et al. (1971b). In the squirrel monkey the angular displacement of the elbow and knee joints is proportional to the accompanying change in length for the 4 muscles we chose to study, the biceps, triceps, quadriceps and hamstrings. The integrated evoked E.M.G. was therefore plotted by computer against the differentiated angular displacement of the joint as determined with a goniometer fitted with a potentiometer, the slope and threshold of the resulting graph serving as a measure of the spasticity. Both the response to varying rates of stretch and to maintained tonic stretch were examined. The quantitative results confirmed our clinical observations. Normal and nonspastic monkeys yielded low flat plots as seen in Figure 4. Spastic animals showed steep plots as seen in Figure 5. Though spasticity usually affected the biceps and quadriceps, all combinations of effect were seen. Just as Burke et al. (1970, 1971) and Lance and Burke (1974) had found in hemiplegic humans, our monkeys demonstrated a linear relationship between integrated evoked E.M.G. and rate of stretch, the steep slopes of the plots indicating a chiefly phasic type of spasticity dependent on the Ia spindle afferents like that in hemiplegic man.

\section{DISCUSSION}

Our finding truly significant spasticity only after bilateral ablations of the primary motor cortex is in agreement with the concensus of published opinion. Though animals with unilateral motor ablations assumed postures resembling those of hemiplegic man and demonstrated increased patellar jerks and might have shown mildly increased muscle tone, this was never sufficient, save in one animal, to be distinguished quantitatively from normal. Subcortical damage was carefully excluded in our experiment by the use of subpial suction with histological control.

An understanding of the mechanism of spasticity (Bard, 1968) began with Sherrington's (1897, 1898 ) work on the decerebrate cat. Muscle tone is governed by a series of centrifugal pathways acting upon interneurons and alphamotoneurons governing the sensitivities of spinal reflex mechanisms. When selective lesions are placed in these pathways their normal balance is upset, the result being the algebraic sum of the 


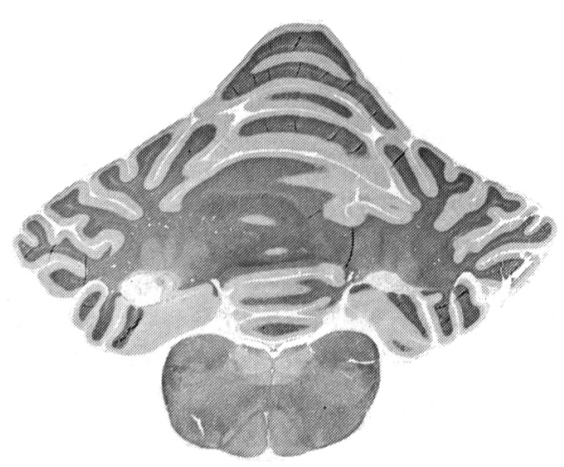

Figure 6-Section through bilateral dentate lesions Monkey M40 Luxol Fast Blue-H \& E stain X 10.

residual activity. Maintaining a tone-enhancing bias are two major systems, the reticulospinal facilitatory extending from the diencephalon to the medulla and mediated bilaterally in the lateral funiculus and the vestibulospinal from Deiter's nucleus distributed ipsilaterally in the ventral funiculus (Goldberber, 1969; Kuypers, 1974; Lawrence and Kuypers, 1965). Muscle tone in spastic preparations dependent only upon caudal brainstem structures, falls dramatically after vestibulospinal interruption whereas in those dependent on more rostral structures it shows little change since the reticular facilitatory system continues to act. Additional mild facilitation is provided by the pyramidal tracts.

Counterbalancing facilitatory effects is the combined inhibitory action of the extrapyramidal cerebral cortex, striatum and ventromedial reticular formation below the level of the trapezoid body. In the subprimate, the anterior lobe of the cerebellum with the fastigial nuclei is also inhibitory to muscle tone. All these inhibitory effects appear to be channeled through the reticular inhibiting system whose effects are bilaterally, but chiefly ipsilaterally, distributed in the ventrolateral funiculus of the spinal cord.

It is with interruption of the powerful cerebral cortical extrapyramidal pathway that we have been concerned in our review of decorticate spasticity and in our own spastic monkeys. Though there has been

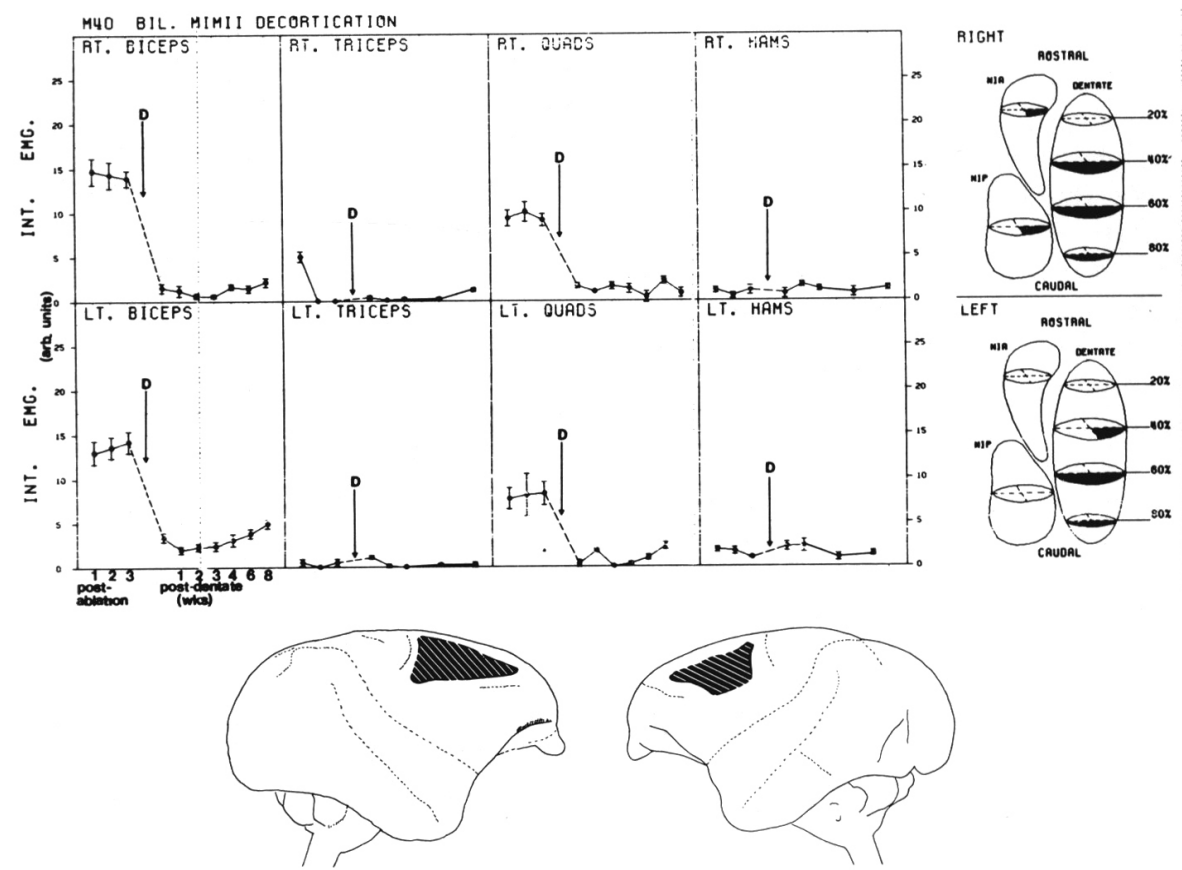

Figure 7-Computer plot of muscle tone against time for same monkey as in Figure 6 after bilateral ablation of primary and supplementary cortex for all 8 muscles studied. Mean integrated E.M.G. evoked by a constant rate of stretch though a constant excursion is plotted against time in weeks. Spasticity is most prominent in biceps and quadriceps. Date of dentatectomy indicated by arrow. At right is a computerized plot determined from serial sections showing site and extent of dentate lesions in black. NIA and NIP indicate the interposed nuclei.

much controversy as to the exact site of the cells of origin of this system, the balance of published experience would place it chiefly in the rostral primary motor cortex, a conclusion with which our experience would agree. However, the exact decision between primary, supplementary, or premotor cortex naturally will depend upon the definitions of the author concerned and our work was not planned to define the precise fraction of cortex involved. Since in the squirrel monkey the supplementary motor cortex extends widely over the convexity with few complicating sulci, it seems unlikely to us that major errors of localization are responsible for our failure to produce spasticity ablating this area.

Since our work and much of that reported in the literature suggests that significant decorticate spasticity depends upon bilateral lesions, this inhibitory effect must be transmitted bilaterally, crossing presumably (Crosby et al., 1966) in the corpus callosum. Otherwise subcortical le- sions would also have to be bilateral to produce significant spasticity and they do not. Once caudal to subcortical structures, the effects are obviously transmitted contralaterally.

\section{THE EFFECT OF DENTATECTOMY ON SPASTICITY}

We now studied the effect of stereotactic dentatectomy on our decorticate spastic models using the atlas by Emmers and Akert (1963) and measuring the effects with the integrated evoked E.M.G. technique.

In contradistinction to clinical teaching and such experimental work as that of Carrea and Mettler (1974) warning that lesions of the dentate nucleus produce devastating ataxia, reported series of dentatectomy in man have not described such a motor deficit perhaps because of avoidance of the interposed nuclei which were also damaged in Carrea and Mettler's monkeys (Sprague in discussing Zervas et al., 1967). We 
performed stereotactic dentatectomy in 6 normal squirrel monkeys, in 4 bilaterally, without discernable persisting deficit.

We then carried out stereotactic dentatectomy in 27 decorticate spastic squirrel monkeys, unilaterally in 13 , bilaterally in 14 as shown in Figure 6. Tone in both biceps, triceps, quadriceps and hamstrings followed quantitatively for varying periods up to 2 months before dentatectomy, was followed up to 3 months postoperatively. The time course was plotted by computer for each muscle alongside a chart of the extent and site of the dentate lesions based on serial sections as shown in Figure 7.

Again clearcut results emerged. Dentatectomy produced, on the average, a $60 \%$ reduction in the degree of spasticity strictly ipsilaterally, the effect being related to the size of the lesion. Bilateral lesions did not enhance the ipsilateral effect.

For comparison, acute experiments were performed on 11 intercollicular and 5 anemic decerebrate cats (Pollock and Davis, 1923). The resulting extensor rigidity, exhibiting both tonic and phasic effects as reported by Burke et al. (1972), was evaluated quantitatively as in the monkey. Bilateral dentatectomy did not alter muscle tone in these preparations.

\section{DISCUSSION}

The paleocerebellum (anterior lobe and fastigial nuclei) and neocerebellum, (posterior lobe and dentate nuclei) (Gilman et al., 1971a) must be considered separately in a study of the role of the cerebellum in governing muscle tone. Sherrington (1897-1898) noted that stimulation of the anterior lobe inhibited, while ablation enhanced, the degree of spasticity in the decerebrate cat. Snider et al. (1941) showed that resection of the anterior lobe enhanced the spasticity of cats with bilateral pericruciate cortical ablations. The spasticity produced by anemic decerebration (Pollock and Davis, 1923) results from damage to the anterior lobe. In normal cats unilateral lesions of the fastigial nuclei produced spasticity in the contralateral extensors and ipsilateral flexors, the reverse pattern to that seen with anterior lobe decortication. In decerebrate cats unilateral caudal lesions of fastigial nucleus reduced tone contralaterally but increased it ipsilaterally, the reverse effect occurring with rostral lesions. Bilateral fastigial lesions enhanced decerebrate rigidity, subsequent lesions of Deiter's nucleus resulting in hypotonia (Batini and Pompeiano, 1957; Chambers and Sprague, 1951; Moruzzi and Pompeiano, 1956; Sprague and Chambers, 1953).

It was difficult to reconcile these findings with the well known observations that total cerebellar ablation and in particular lesions of the posterior lobe resulted in hypotonia in man and other primates. The more so when it was realized that all Purkinje cells (Sprague and Chambers, 1953) were inhibitory to the cerebellar and vestibular nuclei which themselves were facilitatory. The explanation came with studies of spindle activity. Beginning with the work of Granit et al. (1955) it soon became apparent that, despite the fact that removing the anterior lobe increased the degree of decerebrate spasticity in cats, the cerebellar lesion diverted that spasticity from a system dependent on intense fusimotor drive to one of virtual paralysis, the hypertonia now becoming dependent on direct drive of alpha motoneurons. This change occurred smoothly without visible behavioural change, the cerebellum acting as a simple switch between the 2 systems. Thus ablation of the anterior lobe removed a tonic facilitation of muscle spindles. In subprimates but not in primates this was presumably accompanied by loss of direct paleocortical inhibition of the vestibulospinal system enhancing alpha motoneuron drive sufficiently to more than compensate for fusimotor paralysis and to maintain the spasticity (Gilman et al., 1971a, 1971b).

But current interest in the role of the cerebellum in spasticity revolves around the hypotonic effects of posterior lobe ablations having been aroused chiefly by clinical studies. Beginning with the unsatisfactory experience of Delmas-Marsalet and
Bogaert (1935) with attempts to suppress Parkinsonian hypertonia by coagulating the dentate nucleus and Toth's (1961) experience with open dentatectomy in human movement disorders, a plethora of publications appeared upon the effects of chiefly stereotactic dentatectomy on human motor disorders from which, unfortunately, few therapeutic guidelines emerged. Heimburger (1970a) suggested that dentatectomy was more useful for spasticity of cerebral than of brainstem origin particularly axial spasticity (Heimburger, 1967; Heimburger and Whitlock, 1965) but at variance with other workers repeatedly reported that the effects were contralateral (Heimburger, 1969, 1970a, 1970b). Siegfried (1971) noted failure in the treatment of spasticity due to multiple sclerosis.

The role of the neocerebellum in spasticity was investigated in the laboratory by Thiele (1905), Weed (1914), Miller and Banting (1922), Warner and Olmsted (1923) showing that cerebellectomy, cerebellar hemispherectomy, superior cerebellar pedunculotomy and dentatectomy reduced spasticity ipsilaterally, Fulton (1936) and Fulton et al. (1932) observed that bilateral cerebral hemispherectomy no longer made monkeys spastic after previous decerebellection, and Crosby et al. (1966) reported that lesions of the posterior vermis and hemispheres reduced the tone of spastic monkeys and humans. But not all investigators were able to demonstrate this neocerebellar hypotonic effect (Ward, 1947). Warner and Olmsted and Weed traced the path of the spasmolytic effects of stimulation after decerebration in cats through the internal capsule, medial $3 \mathrm{rd}$ of peduncle, and frontopontine tract. Langworthy (1928) reported that in 9 cats bilateral section of the middle cerebellar peduncle produced extensor spasticity similar to that seen after bifrontal cerebral lesions. Sprague and Chambers (1953), however, were unable to alter the degree of decerebrate rigidity after unilateral or bilateral lesions of the interpositus nuclei.

Studies with stimulation reviewed by Dow and Moruzzi (1958) have 
given uncertain results. Nulsen et al. (1948) inhibited the motor effects of stimulation of the motor cortex or pyramid by dentate stimulation, enhanced them by fastigial stimulation, but the effect varied with the parameters used. Adrian et al. (1958) and Henatsch et al. (1964), stimulating the cerebellar nuclei in acute intercollicular decerebrate cats, produced varied effects on spindle activity in hindlimb extensors though the effects of stimulating the fastigial or interpositus nuclei were chiefly facilitatory.

The dentate nucleus being the main recipient of neocerebellar cortical efferents and projecting via thalamus to motor cortex, it had long been postulated that these structures constituted a neocerebellar facilitatory pathway for the control by cerebral cortex of myotatic reflexes (Gilman et al., 1971b). Gilman pursued this matter further by demonstrating that cerebellectomy including the deep nuclei permanently reduced the response of spindle afferents in the medial gastrocnemius to stretch, an effect that could be duplicated by severing the superior cerebellar peduncle or pyramid. Since the effects of cerebellectomy and pyramidotomy were not additive it was thought that the neocerebellar facilitatory pathway was mediated by the pyramidal tract (Gilman, 1969; Gilman and Ebel, 1970; Gilman et al., 1974; Gilman and Marco, 1971; Gilman and McDonald, 1967; Sprague and Chambers, 1953). Though this concept was supported by Gilman's (1971a) demonstration of a similar suppression of spindle activity by lesions of the ventrolateral nucleus, the abolition of this suppressive effect by lesions not of the sensorimotor cortex, but rather of the tegmentum, reported by others suggested an alternate route for the distribution of neocerebellar facilitation.

Our results provide further evidence for the existence of a neocerebellar pathway facilitatory for muslce tone. This appears to be the first laboratory evidence supporting the clinical experience that dentatectomy suppresses spasticity of cerebral but not of brainstem origin, the effect being strictly ipsilateral. It is unlikely that the pathway through which this effect is distributed in our animals involves either the cerebral cortex or the ventrolateral nucleus of thalamus since the effect was seen after extensive bilateral frontal decortication. Moreover, it is a well known clinical fact that lesions of ventrolateral nucleus, unlike those of dentate, fail to suppress spasticity. Presumably more caudal brainstem structures are involved. Since the effect of dentatectomy was strictly ipsilateral the anatomy of these structures must allow appropriate unilateral propagation. Could rubrospinal pathways be the answer? Dentatectomy was without effect in our decerebrate and anemic decerebrate cats presumably because these preparations lacked those more rostral brainstem structures in which dentatotegmental interplay takes place.

It is difficult to reconcile our findings in decerebrate cats with the early work showing that total cerebellectomy or superior cerebellar pedunculotomy prevented or abolished spasticity, unilateral lesions ipsilaterally, unless the difference is due to the limited extent of our dentate lesions. Miller and Banting's (1922) finding that dentate ablations also counteracted decerebrate rigidity, since it is not carefully documented, is difficult to assess. The fact remains that our experiments demonstrated a striking ipsilateral sensitivity of simian decorticate spasticity to stereotactic dentatectomy not seen with feline decerebrate rigidity.

\section{DISCUSSION}

Bates (London, England) queried whether the term "rigidity" should not have been used, as opposed to "spasticity", as the slides indicated a linear relation beteen integrated EMG and velocity rather than displacement. He also suggested that the observations on dentatectomy might have been due to some type of less specific postoperative shock phenomenon, since Fulton and Soriano had shown that cerebellectomy on the side of a cortical ablation increased spasticity:

Girvin (London) also expressed concern about the lack of distinction between rigidity and spasticity, even though both were results of involvement of extrapyramidal pathways and frequently components of each were combined in clinical cases. There were, however, well defined differences such as: (1) the presence or absence of hyperreflexia, irradiation or reflexes, and clonus; (2) the distribution of increased tone in protagonist and antagonist muslces; and (3) the characteristics of the response (resistance) to velocity or displacement. Tasker answered that his animals had been followed for varying periods, some up to 15 months. They had stable spasticity for 2 months prior to dentatectomy. In some of the latter there was damage to nucleus interpositus and the lesion never accomplished a pure bilateral complete dentatectomy, but no other vital structures were considered to have been injured. With respect to the spasticity-versus-rigidity question, he considered that historically, and still persistent in the literature, there was much confusion in the use of the terms and that to differentiate them absolutely was probably not warranted.

Murphy (Toronto) cautioned that muscle tone can be assessed only by passive movement of the limbs, with resultant sensory input from muscles, joints, and other receptors. This method mimics many of the experimental situations which have been described at the Symposium and accordingly it would be expected that a number of supraspinal pathways, including transcortical reflexes, would be activated. The combination of suprasegmental and segmental influences, involving facilitation and inhibition of both alpha and gamma motor neurons, could give rise to a number of different abnormalities. Thus he considered it an oversimplification to have only two words, "spasticity" and "rigidity", to describe what is perhaps a continuum of abnormalities of muscle tone.

Marshall (Ottawa) enquired whether there were alterations of tone on the two sides after unilateral dentatectomy. In reply Tasker answered that all the data had not yet been collated on the approximately 12 spastic animals with unilateral, and 14 bilateral, dentatectomies. In general, however, he considered that (1) the resulting decreased tone appeared to be the result of only an ipsilateral lesion; (2) within a given muscle group a bilateral lesion was no more effective than the ipsilateral lesion; and (3) the degree of resulting hypotonicity appeared to be proportional to the volume of dentate nucleus destroyed.

ACKNOWLEDGEMENT: The assistance and advice of Dr. Peter Ashby, Neurology Division, Toronto Western Hospital, particularly with respect to the use of the integrated evoked E.M.G. technique and its computerized display is gratefully acknowledged.

\section{REFERENCES}

ADRIAN, H., HOLMGREN, B., LEA-PLAZA, $H$., and PAZ, R. (1958) Les influences des noyaux du cervelet sur les fuseaux neuromusculaires. Revue neurologique 98, 700-708.

AKERT, K. (1964). Comparative anatomy of frontal cortex and thalamofrontal connections in: - The 
frontal granular cortex and behaviour: Warren and Akert, editors. McGraw Hill \& Co., New York. BARD, P. (1968) In Medical Physiology 12 ed. Vol. II, V. B. Mountcastle editor. C. V. Mosby \& Co., St. Louis.

BARD, P., BROOKS, C.M. and WOOLSEY, C. N. (1934). Decorticate and decerebrate rigidities in the cat. Am. J. Physiol. 109, 5.

BARD, P and RIOCH, D., McK. (1937) A study of four cats deprived of neocortex and additional portions of the forebrain. Bull-Johns Hopkins Hospital. 60, 73-148.

BATINI, C. and POMPEIANO, O. (1957). Chronic fastigial lesions and their compensations in the cat. Arch. ital. Biol. 95, 147-165.

BENJAMIN, R. M. and WELKER, W. I. (1957). Somatic receiving areas of cerebral cortex of squirrel monkey (Saimiri sciureus) J. Neurophysiol. 20, 286-289.

BIEBER, I. and FULTON, J. F. (1938). Relation of the cerebral cortex to the grasp reflex and to postural and righting reflexes. Arch. Neurol. and Psychiat. 39, 433-454.

BROWN, J. W. (1973). Treatment of spasticity by pulvinectomy. Lancet Aug. 4, 68.

BUCY, P.C. and FULTON, J. F. (1933). Ipsilateral representation in the motor and premotor cortex of monkeys. Brain 56, 318-342.

BUCY, P. C., KEPLINGER, J. E. and SIQUEIRA, E. B. (1964). Destruction of the "Pyramidal Tract" in man. J. Neurosurg. 21, 385-398.

BUCY, P. C., LADPLI, R. and EHRLICH, A. (1966). Destruction of the pyramidal tract in the monkey. J. Neurosurg. 25, 1-23.

BURKE, D., GILLIES, J. D. and LANCE, J. W. (1970). Quadriceps stretch in human spasticity, J. Neurol. Neurosurg. Psychiat. 33, 216-223.

BURKE, D., GILLIES, J. D. and LANCE, J. W. (1971). Hamstrings stretch reflex in human spasticity. J. Neurol. Neurosurg. Psychiat. 34, 231-235.

BURKE, D., KNOWLES, L., ANDREWS, C. and ASHBY, P. (1972). Spasticity: Decerebrate rigidity and the clasp-knife phenomenon: An experimental study in the cat. Brain 95, 31-48.

CANNON, B. W., MAGOUN, H. W. and WINDLE. (1944). Paralysis with hypotonicity and hyperreflexia subsequent to section of basis pedunculi in monkeys. J. Neurophysiol. 7, 425-437.

CARREA, R. M. E. and METTLER, E. A. (1947). Physiologic consequences following extensive removals of the cerebellar cortex and deep cerebellar nuclei and effect of secondary cerebral ablations in the primate. J. Comp. Neurol. 87, 169-288.

CHAMBERS, W. W. and SPRAGUE, J. M. (1951). Differential effects of cerebellar anterior lobe cortex and fastigial nuclei on postural tonus in the cat. Science 114, 324-325.

COOPER, I. S. (1973). Effect of chronic stimulation of anterior cerebellum on neurological disease. Lancet Jan. 27. 206.

COOPER, I. S. AMIN, I., CHANDRA, R. and WALTZ, J. M. (1973a). A surgical investigation of the clinical physiology of the LP pulvinar complex in man. J. Neurol. Sci. 18, 89-110.

COOPER, I. S., CRIGHEL, E. and AMIN, I. (1973b). Clinical and physiological effects of stimulation of the paleocerebellum in humans. J. Am. Geriat. Soc. 21, 40-43.

COOPER, I. S. and GILMAN, S. (1973). Chronic stimulation of the cerebellar cortex in the therapy of epilepsy in the human: In Neural. Organization and its relevance to prostheses. W. S. Fields, editor. Pages 371-375 Intercontinental Media Book Corp., New York and London.
COOPER, I. S., WALTZ, J. M. AMIN, I. and FUJITA, S. (1971). Pulvinectomy: A preliminary report, J. Amer. Geriat. Soc. 19, 553-554.

COXE, W. S. and LANDAU, W. M. (1965). Observations upon the effect of supplementary motor cortex ablation in the monkey. Brain 88, 763-772.

CROSBY, E. C., SCHNEIDER, R. C., DEJONGE, B. R. and SZONYI, P. (1966). The alterations of tonus and movements through the interplay between the cerebral hemispheres and the cerebellum. J. Comp. Neurol. 127, Suppl. I, 1-91.

DELMAS-MARSALET, P. P. and BOGAERT, L. VAN (1935). Sur un cas de myoclonies rhythmiques continues déterminées par une intervention, chirurgicale sur le tronc cérébral. Rev. Neurologique $64,728-740$.

DENNY-BROWN, D. (1963). The premotor syndrome in relation to extrapyramidal symptoms. Int. J. Neurol. 4, 21-38.

DENNY-BROWN, D. (1964). The extrapyramidal system and postural mechanisms. Clin. Pharmacol. Ther. 5, 812-827.

DENNY-BROWN, D. (1965). The nature of dystonia. Bull. N.Y. Acad. med. 41, 818-869.

DENNY-BROWN, D. and BOTTERELL, E. H. (1947). The motor functions of the agranular frontal cortex: in The Frontal Lobes Proc. Ass. Res. in Nerv. and Mental Disease, 27, 235-345.

DENNY-BROWN, D., GILMAN, S. and VAN DER MEULEN, J. (1965). Dystonic motor disorder resulting from cortical lesions in the monkey. Exc. Med. 94, 132-133.

DIVITIIS, E., DE SIGNORELLI, C. D. and CERILLO, A. (1972). Stereotaxic surgery for non Parkinsonian dyskinesias. Neurochir. 3, 92-95.

DOW, R. S. and MORUZZI, G. (1958). The physiology and pathology of the cerebellum. U. of Minn. Press, Minneapolis.

DUSSER DE BARENNE, J. G. and MAGNUS, R. (1920). Beitrage zum Problem der Körperstellung III Mitteilung. Die Stillreflexe bei der grosshirnlosen Katze und dem grosshirnlosen Hunde. Pflügers Arch. $\mathrm{d}$ ges Physiol. 180, 75-89.

EMMERS, R. and AKERT, K. (1963). A stereutactic atlas of the squirrel monkey (Saimirisciureus). U. of Wis. Press, Madison.

FÖRSTER, O. (1934). Uber die Bedeutung und Reichwerte des Lokalizations prinzips im Nervensystem. Verhandl. d. deutsch. Gesellsch. f. inn Med. 46, 117-211.

FÖRSTER, O. (1936). The motor cortex in man in the light of Hughlings Jackson's doctrines. Brain $59,135-159$.

FULTON, J. F. (1935). A note on the Definition of the "Motor" and "Premotor" areas. Brain 58, 311-316.

FULTON, J. F. (1936). The interrelationships of cerebrum and cerebellum in the regulation of somatic and autonomic functions. Medicine 15 , 247.306 .

FULTON, J. F. (1937). Spasticity and the frontal lobes: A review. New Eng. J. Med. 217, 1017-1024.

FULTON, J. F. (1949). Physiology of the Nervous system. 3rd edition Oxford Univ. Press, New York.

FULTON, J. F. and KENNARD, M. A. (1934). A study of flaccid and spastic paralysis produced by lesions of the cerebral cortex in primates: in Localization of function in the cerebral cortex. An investigation of the most recent advances. Proc. Ass. for Res. in Nerv. and Mental Disease 13, 158-210.

FULTON, J. F., LIDDELL, E. G., RIOCH, D. McK. (1932). Relation of the cerebrum to the cerebellum I Cerebellar tremor in the cat and its absence after removal of the cerebral hemis- pheres. Am. Med. Ass. Arch. Neurol. Psychiat. 28, 542-570.

GENTILI, F and TASKER, R. R. (In preparation). Decorticate spasticity in the squirrel monkey. A quantitative assessment.

GENTILI, F. and TASKER, R. R. (In preparation). Quantitative assessment of effect of stereotactic dentatectomy on decorticate spasticity in the squirrel monkey.

GILMAN, S. (1969). The mechanism of cerebellar hypotonia: An experimental study in the squirrel monkey. Brain 92, 621-638.

GILMAN, S. and EBEL, H. C. (1970). Fusimotor neuron responses to natural stimuli as a function of prestimulus fusimotor activity in decerebellate cats. Brain Res. 21, 367-384.

GILMAN, S., LIEBERMAN, J. S. and COPACK, P. (1971a). A thalamic mechanism of postural control. Int. J. Neurol. 8, 260-275.

GILMAN, S., LIEBERMAN, J. S. and MARCO, L. A. (1974). Spinal mechanisms underlying the effects of unilateral ablation of areas 4 and 6 in monkeys. Brain 97, 49-64.

GILMAN, S. and MARCO, L. A. (1971). Effects of medullary pyramidotomy in the monkey I. Clinical and electromyographic abnormalities. Brain 94, 495-514.

GILMAN, S., MARCO, L. A. and EBEL, H. C. (1971b). Effects of medullary pyramidotomy in the monkey II. Abnormalities of spindle afferent responses. Brain 94, 515-530.

GILMAN, S. and McDONALD, W. I. (1967). Cerebellar facilitation of muscle spindle activity. J. Neurophysiol. 30, 1494-1512.

GILMAN, S. and VAN DER MEULEN, J. P. (1966). Muscle spindle activity in dystonic and spastic monkeys. Arch. Neurol. 14, 553-563.

GOLDBERGER, M. E. (1969). The extrapyramidal system of the spinal cord II. Results of combined pyramidal and extrapyramidal lesions in the macaque. J. Comp. Neurol. 135, 1-26.

GRANIT, R., HOLMGREN, B and MERTON, P. A. (1955). The two routes for excitation of muscle and their subservience to the cerebellum. J. Physiol. 130, 213-224.

GROWDON, J. H., CHAMBERS, W. W. and LIU, C. N. (1967). An experimental study of cerebellar dyskinesia in the rhesus monkey. Brain 90, 603-632.

HASSLER, R, and RIECHERT, T, (1961). Wirkungen der Reizungen and Koagulationen in der Stammganglien bei stereotaktischen. Hirnoperationen Nervenazt. 32, 97-109.

HEIMBURGER, R. F. (1967). Dentatectomy in the treatment of dyskinetic disorders. Confin. Neurol. 29, 101-106.

HEIMBURGER, R. F. (1969). The Role of the cerebellar nuclei in Dyskinetic Disorders. Confin. Neurol. 31, 57-72.

HEIMBURGER, R. F. (1970a). The role of the cerebellar nuclei in spasticity. Confin. Neurol. 32, 105-113.

HEIMBURGER, R. F. (1970b). The cerebellum and spasticity. Int. J. Neurol. 7, 232-243.

HEIMBURGER, R. F. and WHITLOCK, C. C. (1965). Stereotaxic destruction of the human dentate nucleus. Confin. Neurol. 26, 346-358.

HENATSCH, H. D., MANNI, E., WILSON, J. H. and DOW, R. S. (1964). Linked and independent responses of tonic alpha and gamma hindlimb motoneurons to deep cerebellar stimulation. $\mathbf{J}$. Neurophysiol. 27, 172-192.

HINES, M. (1936). The anterior border of monkey's (Macaca Mulatta) motor cortex and the production of spasticity. Am. J. Physiol. 116, 76.

HINES, M. (1937). The "Motor" Cortex. Bull. Johns Hopkins Hosp. 60, 313-336. 
HINES, M. (1960). The control of muscular activity by the central nervous system: in Structure and Function of Muscle. Bourne, editor. Vol. II, 467-516.

HITCHCOCK, E. (1973). Dentate lesions for involuntary movement. Proc. Roy Soc. Med. 66, 877-879.

JACKSON, H. (1869). 2nd Goulstonian lecture. Brit. Med. J. Mar 6, quoted by Hines, M. (1937).

KENNARD, M. A., and FULTON, J. F. (1933). The localizing significance of spasticity, reflex grasping, and the signs of Babinski and Rossolimo. Brain 56, 213-225.

KING, W. T. (1927). Observations on the role of the cerebral cortex in the control of the postural reflex. Am. J. Physiol. 80, 311-326.

KRAUS, H., SLUGA, E. and TSCHABITSCHER, H. (1970). Bilateral cerebellar hemispherectomy in cases of ataxic symptoms and signs. Int. J. Neurol. 7, 283-287.

KRAYENBÜHL, H. and SIEGFRIED, J. (1972). Dentatectomies or thalamotomies in the treatment of hyperkinesia. Confin. Neurol. 34, 29-33.

KRUGER, L. and PORTER, P. (1958). A behavioural study of the functions of the rolandic cortex in the monkey. J. Comp. Neurol. 109, 439-469.

KUYPERS, G. J. M. (1974). Recovery of motor function in rhesus monkeys. Neurosciences. Res. Progr. Bull, 12, 240-247.

LAITINEN, L. V. (1970). Neurosurgery in cerebral palsy. J. Neurol. Neurosurg. Psychiat. 33, 513-518.

LANCE, J. W. and BURKE, D. (1974). Mechanisms of spasticity. Arch. Phys. Med. Rehab. 55, 332-337.

LANGWORTHY, O. R. (1928). The area frontalis of the cerebral cortex of the cat, its minute structure and physiological evidence of its control of the postural reflex. Bull. Johns Hopkins Hosp. 42, 20-65.

LAUGHTON, N. B. (1928). Studies on the occurrence of extensor rigidity in mammals as a result of cortical injury. Am J. Physiol., 85, 78-90.

LAWRENCE, D. G. and KUYPERS, G. J. M. (1965). Non-pyramidal pathways in monkeys: anatomical and functional correlation. Science $148,973-975$

LEYTON, A. S. F. and SHERRINGTON, C. S. (1917). Observations on the excitable cortex of the chimpanzee, orang-utan and gorilla. Quart J. Physiol. 11, 135-222.

MAGNUS, R. and RADEMAKER, G. G. J. (1923). Red nucleus and posture. Schweiz Arch. f Neurol. u Psychiat. 13, 408-411.

MARTIN, J. K. (1960). Cerebral palsy in Manitoba. Can. Med. Ass. J. 82, 411-417.

MASPES, P. E. and PAGNI, C. A. (1964). Surgical treatment of dystonia and choreoathetosis in in fantile cerebral palsy by pedunculotomy. Pathophysiological observations and therapeutic results. J. Neurosurg. 21, 1076-1086.

METTLER, F. A. (1943). Extensive unilateral cerebral removals in the primate: physiologic effects and resultant degeneration. J. Comp. Neurol. 79 , 185-245.

METTLER, F. A. (1944). Physiologic effects of bilateral simultaneous frontal lesions in the primate. J. Comp. Neurol,. 81, 105-133.

METTLER, F. A. (1967). Decorticate and decerebrate rigidity. Trans. Am. Neurol. Ass. 92, 42-45.

MILES, R. C. and BLOMQUIST, A. J. (1960). Frontal lesions and behavioural deficit in monkey. J. Neurophysiol. 23, 471-484.

MILLER, F. R. and BANTING, F. G. (1922). Observations on cerebellar stimulations. Brain 45 , 104-112.
MORUZZI, G, and POMPEIANO, O. (1956) Crossed fastigial influence on decerebrate rigidity J. Comp. Neurol. 106, 371-391.

McKIBBEN, P. S. (1929). Experiments on the motor cortex of the cat. Anat. Rec. $42,57$.

McKIBBEN, P. S. and WHEELIS, D. R. (1932) Experiments on the motor cortex of the cat. J. Comp. Neurol. 56, 373-389.

NÁDVORNíK, P., ŠRAMKA, M. LISÝ, L. and SVICKA, I. (1972). Experiences with dentatectomy. Confin. Neurol. 34, 320-324.

NASHOLD, B. S, and SLAUGHTER, D. G. (1969). Effects of stimulating or destroying the deep cerebellar regions in man. J. Neurosurg. 31, 172-186.

NASHOLD, B. S., SLAUGHTER, D. G. and HARRISON, J. (1969). A stereotaxic approach and evaluation of the cerebellar nuclei in man. Confin. Neurol. 31, 56.

NULSEN, F. E., BLACK, S. P. W. and DRAKE, C. G. (1948). Inhibition and facilitation of motor activity by the anterior cerebellum. Fed. Proc. 7, 86-87.

OLMSTED, J. M. D. and LOGAN, H. P. (1925). Lesions in the central cortex and extension rigidity in cats. Am. J. Physiol. 72, 570-582.

PEDERSEN, E. (1974). Clinical assessment and pharmacological therapy of spasticity. Arch. Phys. Med. Rehab. 55, 344-354.

PENFIELD, W. and EVANS, J. (1935). The frontal lobes in man: a clinical study of maximum removals. Brain 58, 115-133.

POLLOCK, L. J. and DAVIS, L. E. (1923). Studies in decerebration I. A method of decerebration. Am. Med. Ass. Arch. Neurol. Psychiat. 10, 391-398.

PRIBRAM, K. H., KURGER, L., ROBINSON, F. and BERMAN, A. J. (1956). The effects of precentral lesions on the behaviour of monkeys. Yale J. Biol. Med. 28, 428-443.

RASMUSSEN, T. (1972). Personal communication.

RIECHERT, T. (1972). The stereotactic techn ique and its application in estrapyramidal hyperkinesia. Confin. Neurol. 34, 325-330.

ROSABAL, F. (1967). Cytoarchitecture of the frontal lobe of the squirrel monkey. J. Comp. Neurol. 130, 87-108.

SACHS, F. (1935). The subpial resection of the corte $x$ in the treatment of Jacksonian epilepsy (Horsley operation) with observations on areas 4 and 6 . Brain 58, 492-503.

SANIDES, F. (1968). The architecture of the cortical taste nerve areas in squirrel monkey (Saimiri sciureus) and their relationships to insular, sensorimotor and prefrontal regions. Brain Res. 8, 97-124.

SCHALTENBRAND, G. and COBB, S. (1931). Clinical and anatomical studies on two cats without neocortex. Brain 53, 449-488.

SCHNEIDER, R. C. and CROSBY, E. C. (1963). The interplay between cerebral hemispheres and cerebellum in relation to tonus and movements. $J$. Neurosurg. 20, 188-196.

SHERRINGTON, C. S. (1897). On reciprocal innervation of antagonistic muscles. Proc. Roy Soc. London 60, 414-417.

SHERRINGTON, C. S. (1898).. Decerebrate rigidity. J. Physiol. 22, 319-332.

SIEGFRIED, J. (1971) Stereotaxic cerebellar surgery. Confin. Neurol. 33, 350-360.

SIEGFRIED, J., ESSLEN, E., GRETENER, U., KETZ, E and PERRET, E. (1970). Functional anatomy of the dentate nucleus in the light of stereotaxic operations. Confin. Neurol. 32, 1-10.
SNIDER, R. S. and WOOLSEY, C. N. (1941). Extensor rigidity in cats produced by simultaneous ablation of the anterior lobe of the cerebellum and the pericruciate areas of the cerebral hemispheres. Am. J. Physiol. 133, 454.

SPRAGUE, J. M. and CHAMBERS, W. W. (1953). Regulation of posture in intact and decerebrate cat I. cerebellum, reticular formation, vestibular nuclei. J. Neurophysiol. 16, 451-463.

THIELE, F. (1905). On the efferent relationship of the optic thalamus and Deiter's nucleus on the spinal cord, with speci al reference to the cerebellar influx theory and the genesis of decerebrate rigidity of Ord and Sherrington. J. Physiol. 32, 358-384.

TOTH, S. (1961). The effect of the removal of the nucleus dentatus in the Parkinsonian syndrome. $J$. Neurol. Neurosurg. Psychiat. 24, 143-147.

TOWER, S. S. (1935). The dissociation of cortical excitation from cortical inhibition by pyramid section and the syndrome of that lesion in the cat. Brain 58, 238-255.

TOWER, S. S. (1940). Pyramidal lesion in the monkey. Brain 33, 36-90.

TRAVIS, A. M. (1955a). Neurological deficiencies after ablations of the precentral motor area in Macaca mulatta. Brain 78, 155-173.

TRAVIS, A. M. (1955b). Neurological deficiencies following supplementary motor area lesion in Macaca mulatta. Brain 78, 174-198.

TRAVIS, A. M. and WOOLSEY, C. N. (1956). Motor performance of monkeys after bilateral partial and total cerebral decortication. Am. J. Phys. Med. 35, 273-310.

WAGLEY, P. F. (1945). A study of spasticity and paralysis. Bull. Johns Hopkins Hosp. 77, 218-274.

WALKER, A. E. and RICHTER, H. (1966). Section of the cerebral peduncle in the monkey. Arch. Neurol. Chicago 14, 231-240.

WALSHE, F. M. R. (1935a). On the "Syndrome of the premotor cortex" (Fulton) and the definition of the terms "Premotor" and "Motor": with a consideration of Jackson's views on the cortical representation of movements. Erain 58, 49-80.

WALSHE, F. M. R. (1935b). The disorders of motor function following an ablation of the "Leg Area" of the cortex in man. Brain 58, 81-85.

WARNER, W. P. and OLMSTED, J. M. D. (1923). The influence of the cerebrum and cerebcllum on extensor rigidity. Brain 46, 189-199.

WARD, A. A. (1947). Decerebrate rigidity. J. Neurophysiol. 10, 89-103.

WEED, L. H. (1914). Observations upon decerebrate rigidity. J. Physiol. 48, 205-227.

WELCH, W. K. and KENNARD, M. A. (1944). Relation of cerebral cortex to spasticity and flaccidity. J. Neurophysiol. 7, 255.

WELKER, W. I., BENJAMIN, R. M., MILES, R. C. and WOOLSEY, C. N. (1957). Motor effects of stimulation of cerebral cortex of squirrel monkey (Saimiri sciureus). J. Neurophysiol. 20, 347-364.

WOOLSEY, C. N. (1933). Postural relations of the frontal and motor cortex of the dog. Brain 56, 353-370.

WOOLSEY, C. N. (1943). A monkey which survived bilateral decortication for 161 days. Fed. Proc. 2, 56.

ZERVAS, N. T. (1970). Paramedial cerebellar nuclear lesions. Confin. Neurol. 32, 114-117.

ZERVAS, N. T., HORNER, F. A. and GORDY, P. D. (1967a). Cerebellar dentatectomy in primates and humans. Trans. Am. Neurol. Ass. 92, 27-30.

ZERVAS, N. T., HORNER, F. A. and PICKREN, K. S. (1967b). The treatment of dyskinesia by stereotaxic dentatectomy. Confin. Neurol. 29, 93-100. 